\author{
Joanna Szmyt \\ Research and Innovation Centre Pro-Akademia \\ 9/11 Innowacyjna Street, 95-050 Konstantynów Łódzki, joanna_szmyt@wp.pl
}

\title{
MODERN REHABILITATION SYSTEMS BASED ON TEXTILES
}

\begin{abstract}
The article presents examples of rehabilitation solutions in which textiles play an important role. They are a fully functional garment, an element of clothing adapted to a given part of the body or a product intended for use in improving health. They are designed with the use of modern production technologies that utilize various raw materials to support the health aspects of the user with their structure and properties.
\end{abstract}

\section{Key words}

Medical compression, electro-stimulation, wholegarment knitted fabrics, spacer knitted fabrics, rehabilitation gloves.

\section{Introduction}

Clothing has accompanied people since prehistoric times, providing protection against adverse external conditions [1]. Textiles still play an integral role in human life. In addition to the basic function of protecting the body against cold and heat, excluding the fashion aspect, they complement many areas of human life connected with our functioning in the home environment, at work, during recreation or while doing sports. One important area is the use of textiles in human health. In selected fields, textiles, including knitted fabrics, are used to improve human health due to their structure and body fit as well as the possibility of extensive customization of properties. The following are examples of the use of knitted fabrics in the field of rehabilitation, where knitted fabrics play an integral role in improving the health of the user.

\section{Medical compression}

This use is very important from the point of view of many branches of patient's health improvement with the use of textiles with standardized properties of compression on selected parts of the body. Compression products are based on knitting technology. These are mostly products manufactured based on the row knitted fabrics technique on double-bearing cylindrical machines with the use of elastomeric yarn. They are designed as wholegarment products or are used for making garments, in order to adjust the product to a given part of the body as much as possible. As serving to improve health, they are widely analyzed and examined, so that the design of the product and its compression features have strictly defined health functions in terms of the pressure on the patient [2 - 12]. One of the solutions used for improving children's health in terms of sensory feelings are products suited to the child's body in the form of flexible orthoses Hylton ${ }^{\circledR}$ Orthotics (Fig.1). They provide support of the child's body and its balance, as well as its response to deep pressure by improving the control of muscle tone and respiratory mechanics. They help reducing reaction time and in involuntary movements, as well as in auto-stimulation behaviors.

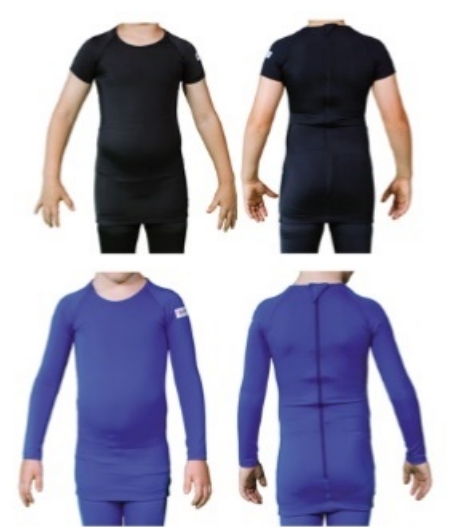

Fig. 1 Compression orthosis of the torso Source: [13] 
These compression orthoses are intended mainly for little patients with childhood cerebral palsy, Down syndrome as well as those diagnosed with muscular atrophy or sensory integration disorders. The second function is to strengthen physical stability and posture control among children with motor function disorders, by means of increased coordination and body awareness, as well as the speed and responsiveness of the child's movements.

Among products with compressible properties, a wide group are pantyhoses with anti-varicose and anti-edema properties. Designed as products with configurable compression, they provide adequate pressure on the body for proper circulation in the lower parts of the body, in pressure classes from $10 \mathrm{mmHg}$ to $32 \mathrm{mmHg}$. The most important task of anti-varicose stocking products is to exert a specific pressure on the patient's legs in order to force the venous blood from the lower parts of the legs towards the heart [2-4, 9] (Fig. 2). These products are designed both as seamless and with the use of a flat seam to provide constant configurable compression [14-15] (fig. 3). Products in the form of pantyhoses, stockings or knee-length socks can also provide a preventive effect for people who work in a standing and sitting position, especially those with strictly medical direction for treatment of lower limb varicose veins.

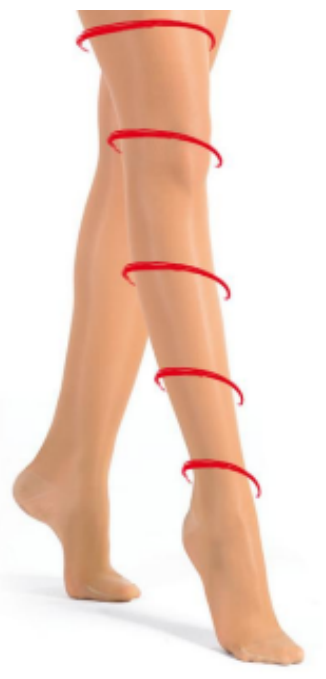

Fig. 2 Anti-varicose stocking Source: [14]

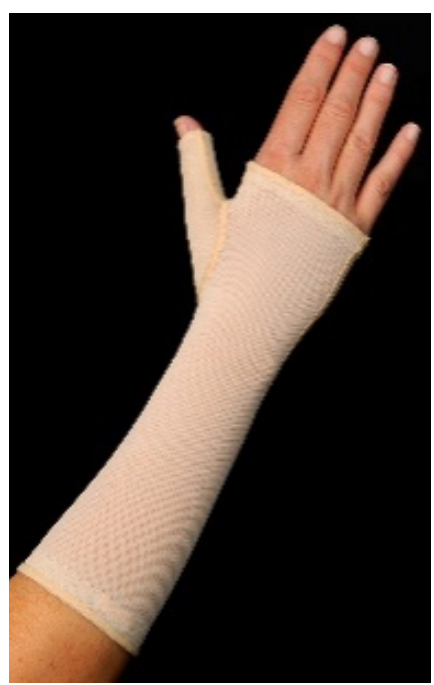

Fig.3 Seamed compression product Source: [15]

The group of products of the type fitted to the user's body includes knitted bands, also in seamless form. They are used to stabilize parts of the body such as wrists or other joints (knee, ankle) (Fig. 4). They provide adequate stiffening and compression at the early stages of degenerative disease as well as during chronic, post-traumatic or postoperative irritations in the joint area [5]. They are also used in prevention to save the occurrence of injuries e.g. during practicing competitive sport. These products, in addition to performing the assumed function, thanks to the use of a variety of raw materials, ensure comfort of use. These include additional features such as moisture dissipation, which ensures antibacterial properties, as well as the introduction of the anti-rheumatic function through the addition of a natural ingredient such as amber (enrichment or fiber) or minerals providing a thermal effect by raising the body temperature, which can further contribute to the process of improving health.

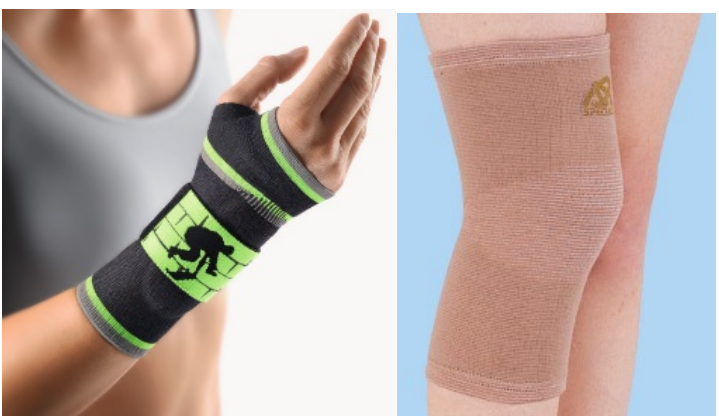

Fig. 4 Stabilizer of the wrist and knee

Source: [16] 
While discussing the functions of textile products in rehabilitation in terms of immobilization of the patient's body parts, it is necessary to emphasize the role of textiles in the construction of a wide group of products with a stabilizing function in the form of orthoses. These are rehabilitation devices used as orthopedic apparatuses for immobilizing joints, body sections or muscle groups, usually replacing plaster dressing (Fig. 5). Their main task is to ensure a stable position of the joints of the limbs which have been injured e.g. sprains, dislocations or ligament ruptures [6-7]. Regardless of the structure of these products, which can be divided into rigid, semi-rigid (semi-flexible) and soft (elastic), textile materials in the form of woven fabrics, knitted fabrics and tapes play a fundamental role in the composition of orthoses.

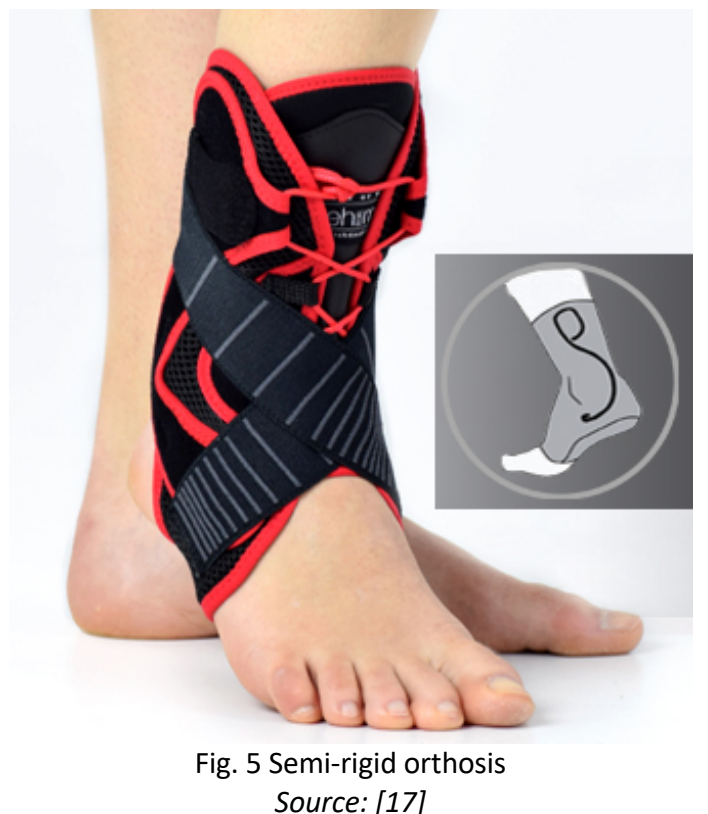

In combination with rigid composite elements of the orthoses, elastic and soft textile materials placed next to the skin, improve the comfort of use as well as act as an air layer ensuring the removal of moisture from the stiffened part of the body. For this purpose commonly, thanks to their spatial structure and elasticity, spacer knitted fabrics (3D) are used, usually made of polyamide produced both the warp and the weft knitted fabric technology.

Nowadays, thanks to their spatial structure and elasticity, (3D) spacer knitted fabrics are used, usually made of polyamide. Orthoses made entirely of textiles are joined using flat seams with lacing elements or Velcros for comfortable stabilization of the injury. Compression effect of textiles also ensures that the temperature around the given joint is raised and maintained at a constant level.

An important application scope of textiles, including knitted fabrics in rehabilitation, is compression therapy as regards scar treatment. In this area, the use of special devices adapted to the structure and needs of the patient is very important during treatment of post-burn and post-operative marks left after wounds have healed [8-9]. Research works [10-12]present the issues of compression products in terms of the value of individual pressure exerted by the product on various parts of the patient's body, so that the designed compression medical product performs a therapeutic function. The effect of the seam and the tolerance performance of the compression product was analyzed, which was dependent on the stiffness of stretching (compression) fabric for selected parts of the body as a function of the complexity of building the female and male figures.

To improve the effectiveness of patient's treatment, the force of pressure on the scar must be chosen appropriately - as specified by the doctor. Too much pressure can lead to tissue necrosis as a result of circulatory disturbance, whereas too little pressure will not have the therapeutic effect. A garment individually matched to the wearer using flat seams to minimize the possibility of irritation, has an appropriate value of compression (Fig. 6). These devices can be used on a cured post-burn wound or scar. They should be worn for at least 6 to 24 months regularly and all day round, until there are clear symptoms of healing (the scar flattening, fading away and softening). 


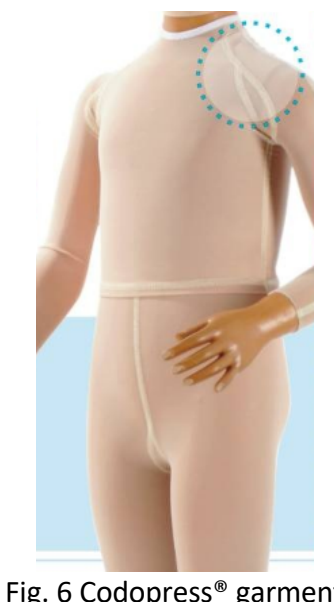

Source: [18]

\section{Anti-bedsore protection}

One of the issues of rehabilitation is protection of patient health or support for treatment in terms of anti-bedsore protection if the patient is immobilized for too long in a sitting or lying position, leading to pressure on the skin. In such conditions, the patient is exposed to pressures, imprints on skin, which in consequence may lead to the formation of bed-sores [19-20].

One of the effective solutions aimed at preventing the creation of bedsores is a textile product made of technical knitted fabric, namely the MEDiMAT ${ }^{\circledR}$ anti-bedsore bed overlay (Figure 7). It is a 'wholegarment' form of 3D spacer knitted fabric with dimensions of $90 \mathrm{~cm} \times 200 \mathrm{~cm}$. Thanks to its spatial form and the structure made of a series of densely arranged monofilaments connecting the upper and lower layers of the flat knitted fabric, it gives the product its elasticity and is a very good substitute for foam. The structure of the product is openwork and highly deformable. It creates a layer between the patient's body and the bed that is permeable to air and moisture. Thanks to these features, it helps to protect the patient from pressures and bedsores, as well as improves the health condition when such inconveniences already exist [21].

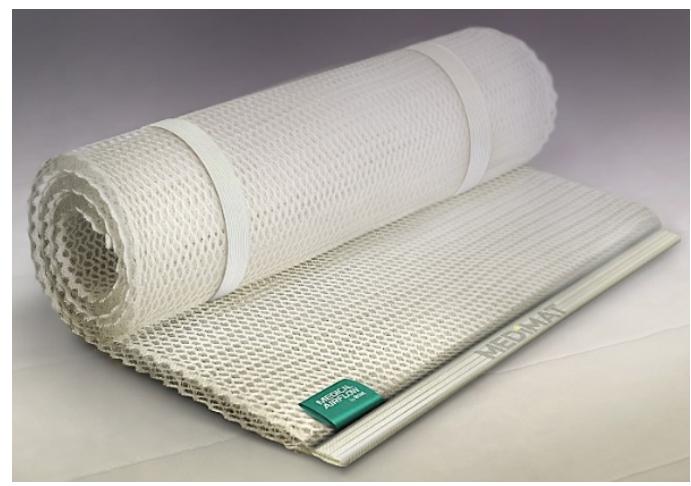

Fig. 7 The MEDiMAT $^{\circledR}$ anti-bedsore overlay Source: [22]

The mat causes an even distribution of the patient's body pressure, eliminating the risk of point loads. The product has gained a positive reputation among patients and physicians after being tested in hospital conditions at the Clinic of Rehabilitation and Physical Medicine in Łódź and has been registered as a medical device.

\section{Rehabilitation gloves}

Interesting solutions aimed at patient health improvement include wholegarment knitted articles for the hand, in the form of gloves. In this type of application, they serve as a carrier for elements of motor nature intended to stimulate the operation of hands and fingers toward making specific moves. Below there are examples of several solutions designed and made for rehabilitation purposes. 
One of them is the so-called Cynteract - a rehabilitation system developed for the hand, consisting in wearing gloves and exercising hand fitness in virtual reality. The system consists of a glove, sensors placed at the ends of its fingers and a tether running along each finger to the control system. It is used for treating hand injuries by controlling their movements, in accordance with a programmed set of exercises. With the help of the orientation sensor placed in the glove, the position of the hand in the room is followed. The position of the strings enables the sensors to precisely detect the movements and bending of each finger. This allows to make exercises in accordance with the rehabilitation program presented in the virtual reality on the screen [23].

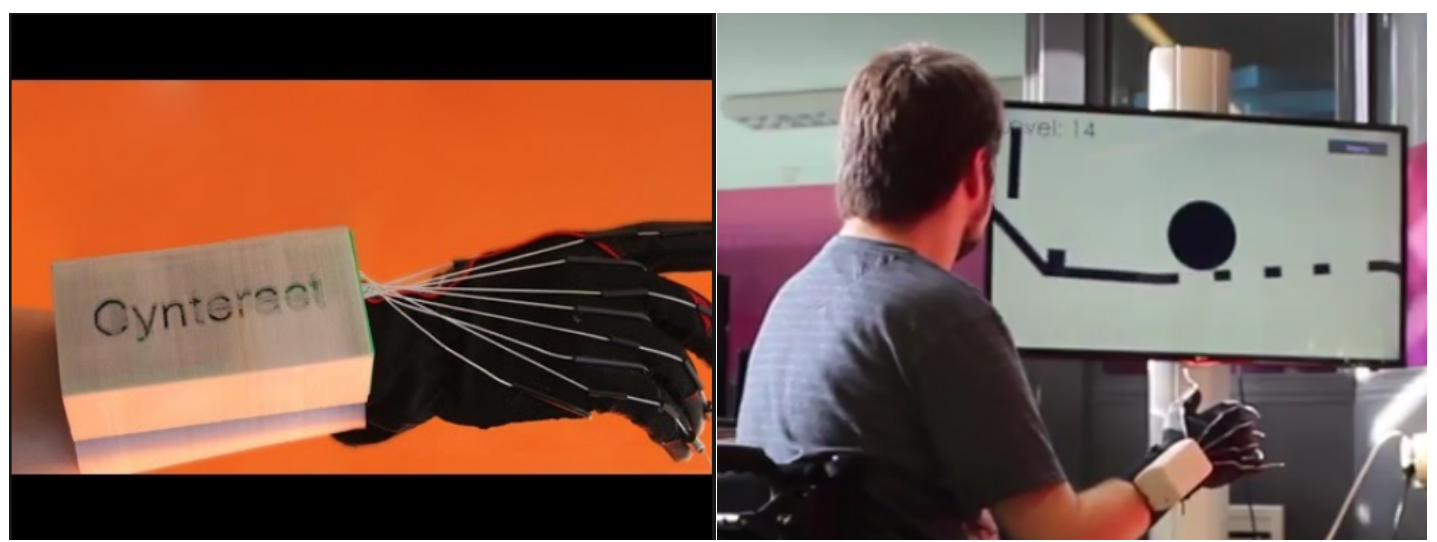

Fig. 8 Cynteract glove for rehabilitation exercises aimed at improving motor performance of the hand Source: [24]

For greater patient motivation to regularly use the gloves and thus exercise, they are connected to virtual reality glasses. Under these conditions, in the virtual world, every hand movement is reconstructed to provide both motor and visual feedback. In this game-like environment, exercises become a pleasure.

A solution based on the use of a glove for hand rehabilitation integrated with a computer program is the robotic system shown in Fig.9. This device is based on a flexible glove of a fitted shape connected with cables attached to each of its fingers and directed along the arm to a rucksack. These 'guides' let the hand movement remote control. The system controls each finger independently. The developed electronics let control the position of fingers as part of arranged rehabilitation program. The programmed mode enables the therapist to properly determine the movements of the glove in order to run a given rehabilitation procedure, allowing for individual selection of the exercise regimen to improve the hand performance, well-being and independence of the patient in terms of everyday functioning in their environment [25-26].

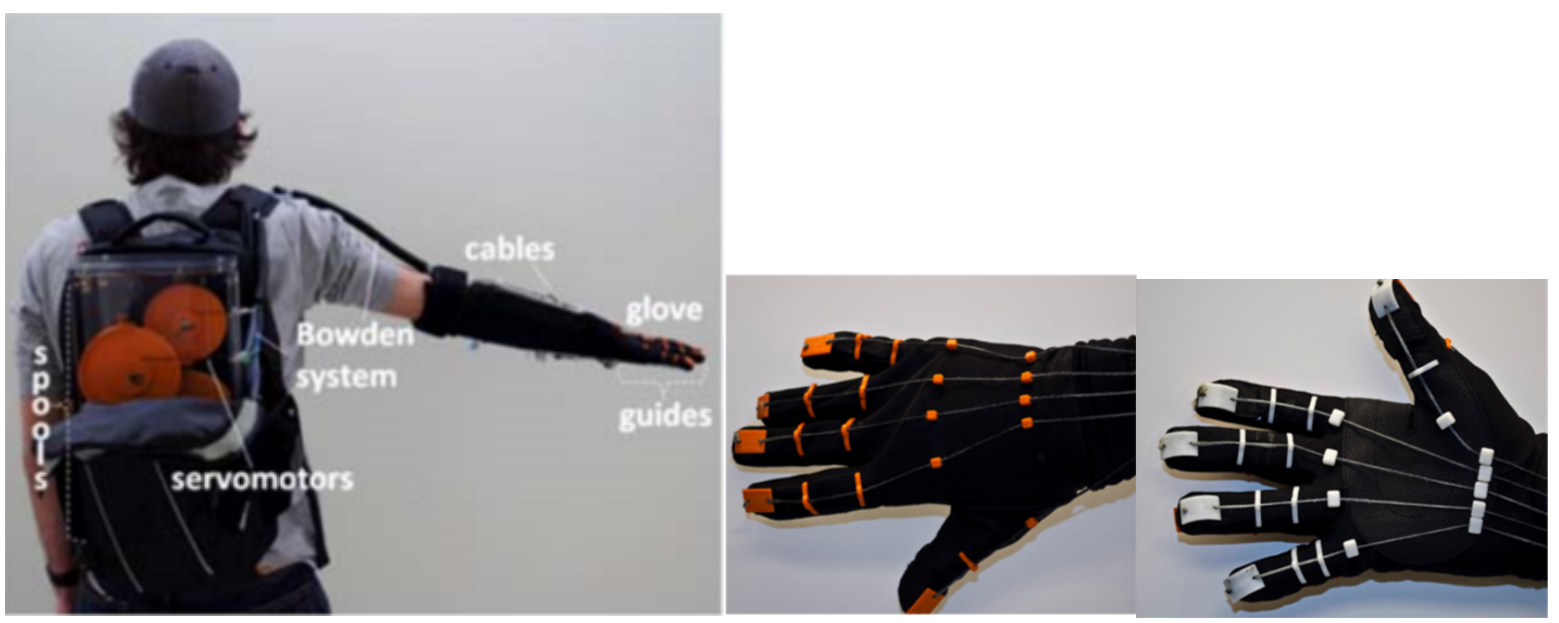

Fig. 9 Prototype of the hand rehabilitation device with a view of the 'guides' Source: [26]

In the context of using textiles as a carrier for stimulation elements, one of the solutions applied to the hand and forearm is a device that directs hand operation for blind people. The device is designed to help coaches of blind athletes participating in the Paralympic Games to learn appropriate muscle 
movements. Until now, trainings consisted in directly moving hands and legs, so that the blind person could remember particular movements and muscle work. Scientists at Imperial College London have developed a device for vibratory feedback, which teaches blind people how to make precise repeatable movements without the presence of a trainer. The 'Ghost' system is able to 'remember' certain movements demonstrated by the trainer. On this basis, an athlete can practice these movements which are monitored on an ongoing basis in terms of accuracy, guided by vibration and sound signals (Fig. 10)

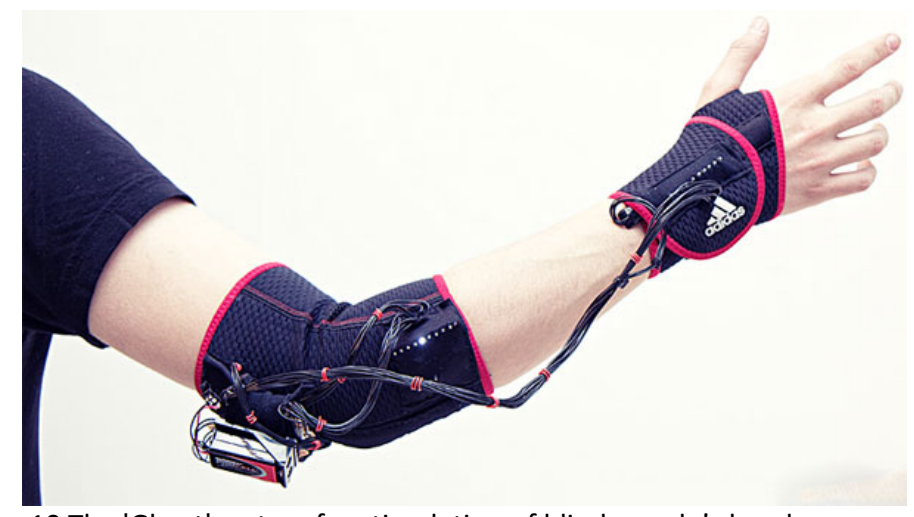

Fig. 10 The 'Ghost' system for stimulation of blind people's hand movements Source: [27]

It is possible to import recordings of movements from other athletes who will be able to follow the movements and techniques of athletes' muscle work improving their own. The authors emphasize that the system has been designed especially for people with disabilities, but in the future the idea will be oriented towards assistance with rehabilitation of people after strokes and other neurological conditions.

\section{Muscle electro-stimulation}

Electro-stimulation of nerves and muscles plays an important role in the field of application of textiles in rehabilitation. Its purpose is to ensure that specific muscles are forced to work in order to improve their condition and function in the field of reeducation of lost muscle function, maintaining or increasing the range of motion in the joints, increasing local blood circulation, or in sports training during regeneration as part of rehabilitation after injuries. This effect is achieved due to a fast change of AC current with different frequency and pulse width in the electrode. The research experimentally determined the conditions of stimulation of muscles of different sizes and their characteristics when using certain FES (Functional Electrical Stimulation) parameters (intensity of stimulation, frequency)[28].

There are many solutions to replace traditional electrodes with those made using conductive textiles based on conductive yarns in the application of fabrics and knitted fabrics [29]. A noteworthy solution for muscle electro-stimulation is based on the silkscreen printing technology in the form of a system of electrodes [30-31].
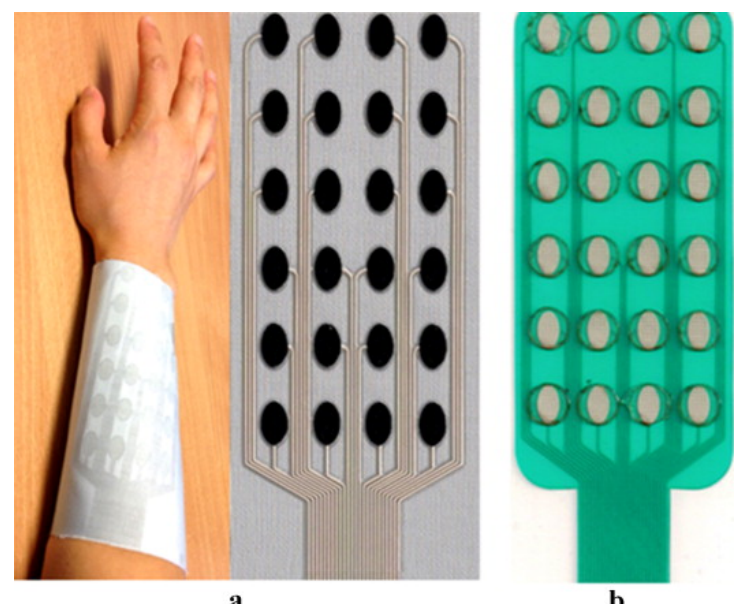

Fig. 11 Flexible printed matrix of electrodes

Source: [32] 
It is based on woven fabric and creates a flexible stimulative device. The advantage is that it does not require the use of a hydrogel layer, it has direct contact with dry skin, becoming a convenient element of therapy (Fig.11). Muscle stimulation was performed using programmable patterns to recreate three different hand gestures. Greater hand gesture recreation was achieved than in the case of application of the most popular printed circuit board with a hydrogel layer. It was concluded that the work of the new textile electrode allows therapeutic work comparable to a typical stimulation electrode. The results allowed further work on application of the electrodes in the form of clothing, the so-called e-textiles.

\section{Summary and conclusions}

Textiles play an important role in products used in medical rehabilitation, especially in areas such as compression therapy and orthopedics. Programmed pressure in shaped and designed products ensuring a specific and constant unit pressure on a selected body part, contributes to the improvement of motor and sensory functions at children with congenital malformations, improvement of health (varicose veins), health effects of accidents treatment (burn wounds) or injuries (e.g., wrist joint). Knitted fabrics used in orthopedic elements provide an increase in the patient's comfort with lighter joint injuries ensuring an improvement of his or her skin condition (protection against abrasions, ventilation, moisture wicking). These features are also provided for the prevention and treatment of pressure ulcers by using spatial tight knit forms to improve the well-being and health, especially of immobilized patients. In addition to the well-developed textronic solutions used for monitoring the patient's vital parameters, in the rehabilitation the textile-based devices are used for improving the hand and arm movements and functions using different solutions based on the structure of the glove or using muscle stimulation therapies.

\section{References}

[1] I. Krucińska. Diagnoza potencjału jednostek badawczo-rozwojowych i procesu komercjalizacji badań, Monograph, Społeczna Wyższa Szkoła Przedsiębiorczości i Zarządzania, Łódź, 2007, pp.6-7

[2] R. Liu, Y.-L. Kwok, Y. Li, T.-T. Lao. Fabric Mechanical-Surface Properties of Compression Hosiery and their Effects on Skin Pressure Magnitudes when Worn. FIBRES \& TEXTILES in Eastern Europe 2010, Vol. 18, No. 2 (79) pp. 91-97.

[3] A. Ilska, K. Kowalski, M. Kłonowska, T. M. Kowalski. Influence of Stress and Relaxation Characteristics of Knitted Fabrics on the Unit Pressure of Compression Garments Supporting External Treatment, FIBRES \& TEXTILES in Eastern Europe 2014, 22, 4(106), pp.87-92.

[4] A. Belbasisa, F. K. Fussa, J. Sidhua. Muscle activity analysis with a smart compression garment, 7th AsiaPacific Congress on Sports Technology, Procedia Engineering 112 (2015), pp. 163 -168.

[5] M. Senthilkumar, L. A. Kumar, N. Anbuman. Design and Development of a Pressure Sensing Device for Analysing the Pressure Comfort of Elastic Garments. FIBRES \& TEXTILES in Eastern Europe, 2012, 20, 1(90), 6469.

[6] W. Trümper, C. Sachse, O. Diestel, C. Cherif. Innovative flat-knitted spacer fabrics for orthoses, Technical Textiles, Aug. 2011, Vol. 54, Issue 4, p.171

[7] D. Ališauskienè, D. Mikučionienè. Influence of the Rigid Element Area on the Compression Properties of Knitted Orthopaedic Supports. FIBRES \& TEXTILES in Eastern Europe 2012; 20, 6A(95): 103-107.

[8] L. Macintyre, M. Baird. Pressure garments for use in the treatment of hypertrophic scars-a review of the problems associated with their use, Burns 32 (2006),pp.10-15

[9] L. Wang, M. Felder, J. Y. Cai. Study of Properties of Medical Compression Fabrics, Journal of Fiber Bioengineering \& Informatics 4:1 (2011),pp.15-22 
[10] E. Maklewska, A. Nawrocki, J. Ledwoń, K. Kowalski. Modelling and Designing of Knitted Products Used in Compressive Therapy. FIBRES \& TEXTILES in Eastern Europe January / December 2006, Vol. 14, No. 5 (59)

[11] A. Ilska, K. Kowalski, M. Kłonowska, T. M. Kowalski, W. Sujka. Issues Regarding the Design of Textile Compression Products for Small Body Circumferences FIBRES \& TEXTILES in Eastern Europe 2016; 24, 6(120): $116-120$

[12] K. Kowalski, K. Karbowski, M. Kłonowska, A. Ilska, W. Sujka, M. Tyczyńska, B. Włodarczyk, T. M. Kowalski. Influence of a Compression Garment on Average and Local Changes in Unit Pressure. FIBRES \& TEXTILES in Eastern Europe 2017; 25, 6(126): 68-74.

[13] www.stanley.poznan.pl

[14] www.pani-teresa.com.pl

[15] www.secondskin.com.au

[16] www.mj-corporation.pl

[17] www.reh4mat.com

[18] www.tricomed.pl

[19] R. M. Allman, C. A. Laprade, L. L. Noel and others. Pressure Sores Among Hospitalized Patients, Ann Intern Med.1986 Sep; 105(3), 37-42.

[20] L. Guttmann. The problem of treatment of pressure sores in spinal paraplegics, British Journal of Plastic Surgery, Vol. 8, 1955-1956, pp. 196-213.

[21] S. F. Tong, J. Yip, K. L. Yick. The possibility of using weft knitted spacer fabric as the wound dressing for pressure ulcer, International Journal of Advances in Science Engineering and Technology, Vol.4, Iss-4, Spl. Issue1 Nov.2016, pp.13-19.

[22] www.bowi.pl

[23] www.cynteract.de

[24] www.emag.medicalexpo.com

[25] M. A. Delph, S. A. Fischer, P. W. Gauthier, C. H. Matrinez Luna, E. A. Clancy, and G. S. Fischer. Development of a Cable Driven Flexible Robotic Rehabilitation Glove, Biomedical Engineering Society Annual Meeting - BMES, Atlanta, GA, October 2012

[26] M. A. Delph, S. A. Fischer, P. W. Gauthier,C. H. Martinez Luna, E. A. Clancy, G. S. Fischer. A Soft Robotic Exomusculature Glove with Integrated sEMG Sensing for Hand Rehabilitation, 13th International Conference on Rehabilitation Robotics (ICORR), Seattle, WA, June 2013

[27] www.medgadget.com

[28] M. Vromansa, P. D. Faghria. Functional electrical stimulation-induced muscular fatigue: Effect of fiber composition and stimulation frequency on rate of fatigue development. Journal of Electromyography and Kinesiology 38 (2018) 67-72.

[29] A. Curteza, V. Cretu, L. Macovei, M. Poboroniuc. The manufacturing of textile products with incorporated electrodes. AUTEX Research Journal, Vol. 16, No 1, March 2016, pp.13-18. 
[30] J. Zieba, M.Frydrysiak, M. Tokarska. Research of Textile Electrodes for Electrotheraphy, FIBRES \& TEXTILES in Eastern Europe, 2011, Vol.19, No.5 (88), pp. 70-74.

[31] M. Kutlu, C. T. Freeman, E. Hallewell, A.-M. Hughes, D. S. Laila. Upper-limb stroke rehabilitation using electrode-array based functional electrical stimulation with sensing and control innovations, Medical Engineering and Physics, 38 (2016), pp.336-379.

[32] K. Yang, C. Freeman, R. Torah, S. Beeby, J. Tudor. Screen printed fabric electrode array for wearable functional electrical stimulation, Sensors and Actuators A: Physical, Volume 213, 1 July 2014, pp. 108-115. 